\title{
Synthesis and characterization of pyrochlore-type yttrium titanate nanoparticles by modified sol-gel method
}

\author{
Z S CHEN ${ }^{1,2}$, W P GONG ${ }^{1,3, *}$, T F CHEN ${ }^{1}$ and $\mathbf{S} \mathbf{L} \mathbf{L I}^{1}$ \\ ${ }^{1}$ State Key Laboratory of Powder Metallurgy, Central South University, Changsha, Hunan 410083, P.R. China \\ ${ }^{2}$ Key Laboratory of Radioactive Geology and Exploration Technology Fundamental Science for National Defense, \\ East China Institute of Technology, Fuzhou, Jiangxi 344000, P.R. China \\ ${ }^{3}$ Electronic Science Department, Huizhou University, Huizhou, Guangdong 516001, P.R. China
}

MS received 29 August 2010; revised 21 October 2010

\begin{abstract}
Pyrochlore-type yttrium titanate $\left(\mathrm{Y}_{2} \mathrm{Ti}_{2} \mathrm{O}_{7}\right)$ nanoparticles were successfully synthesized by a simple soft-chemistry technique viz. citric acid sol-gel method (CAM). The preparation process was monitored by X-ray diffraction, thermogravimetric-differential thermal analysis and Fourier transform-infrared experiments and the microstructures and average size of as-prepared products were characterized by transmission electron microscopy and high resolution transmission electron microscopy images. It was found that compared with traditional solid state reaction (SSR), $\mathrm{Y}_{2} \mathrm{Ti}_{2} \mathrm{O}_{7}$ nanopowders were synthesized at a relatively low temperature $\left(750^{\circ} \mathrm{C}\right)$ for shortened reaction time. Detailed analysis showed that the as-prepared $\mathrm{Y}_{2} \mathrm{Ti}_{2} \mathrm{O}_{7}$ with good dispersibility and narrow size distribution were quasi-spherical; the average size was about $20-30 \mathrm{~nm}$, also, the obtained products had higher BET surface area $\left(50 \mathrm{~m}^{2} / \mathrm{g}\right)$. These properties are very helpful for a photocatalyst to achieve excellent activity and may result in better behaviour in hydrogen storage.
\end{abstract}

Keywords. Yttrium titanate; sol-gel method; synthesis.

\section{Introduction}

Classical pyrochlore oxides, written using the general formula $\mathrm{A}_{2} \mathrm{~B}_{2} \mathrm{O}_{7}$ (where $\mathrm{A}$ is normally the larger trivalent cation and $\mathrm{B}$ the smaller quadrivalent one), exhibit space group $F d 3 m$ with eight formula units within the face-centred cubic unit cell (Subramanian et al 1983). Mostly, A is a trivalent rare-earth ion, but can also be a mono-, divalent cation, and B may be $3 d, 4 d$ or $5 d$ transition elements having an appropriate oxidation state required for charge balance to give rise to the composition, $\mathrm{A}_{2} \mathrm{~B}_{2} \mathrm{O}_{7}$. This structure is closely related to fluorite and can be considered as an ordered, defective fluorite structured materials with anion vacancies (Erickson et al 2002; Stanek et al 2002). Owing to their unique structural characteristics, pyrochlore oxides show high chemical stability, high catalytic activity, high melting temperature, relatively low conduction temperature and excellent ion conductivity. Yttrium titanate $\left(\mathrm{Y}_{2} \mathrm{Ti}_{2} \mathrm{O}_{7}\right)$, one of the typical pyrochlore compounds, recently has received considerable attention as a possible candidate for application as oxygen-ion conductor (Shlyakhtina et al 2008; Wuensch et al 2000), alternative materials to immobilize nuclear solid waste (in particular, actinides) (Ewing et al 2004; Pace et al 2005), photocatalyst for water-splitting to produce hydrogen

\footnotetext{
*Author for correspondence (weiping_gong@mail.csu.edu.cn)
}

(Higashi et al 2005; Abe et al 2006), host materials for efficient $\mathrm{Er}^{3+}$ luminescence (Jenouvrier et al 2005; Ting et al 2010), ceramic pigment (Ishida et al 1993; Pailh et al 2009) and hydrogen storage material (Zhang et al 2009).

Usually, yttrium titanate has been prepared by traditional solid state reaction (SSR), i.e. by heat treatment of a stoichiometric mixture of yttria and titania at high temperature for long reaction time $\left(1300^{\circ} \mathrm{C}\right.$ for $40 \mathrm{~h}$ or $1500^{\circ} \mathrm{C}$ for several h) (Ault and Welch 1966). And also, repeated cycles of grinding and firing of starting oxide components are required to complete the solid state reaction. In spite of this, high pure, composition-homogenous, and nanoscale products are difficult to obtain. Compared with bulk materials, nano-structured ones exhibit outstanding physio-chemical properties; it, therefore, is of great significance to develop alternative synthesis route for pyrochlore $\mathrm{A}_{2} \mathrm{~B}_{2} \mathrm{O}_{7}$ nanoparticles at relatively low temperature. Recently, several softchemistry methodologies, such as coprecipitation (Hector and Wiggin 2004) and sol-gel method (Lin et al 2007), and hydrothermal approach (Li et al 2006b; Tang et al 2009), have been attempted to prepare nanoscale pyrochlore oxides under relative mild conditions. One of the widely used sol-gel methods, the Pechini approach, developed by Pechini in 1967, is based on a polymeric precursor, in which metal ions are uniformly distributed. During the calcination step the polymeric network collapses and the metal oxide powder is left. The powders 
are extremely pure and highly homogeneous compared to powders prepared with conventional methods. The aim of this contribution is to exploit citric acid as chelator to prepare high-pure pyrochlore-type $\mathrm{Y}_{2} \mathrm{Ti}_{2} \mathrm{O}_{7}$ nanoparticles at lower reaction temperature.

\section{Experimental}

\subsection{Synthesis of yttrium titanate nanoparticles}

Yttrium titanate nanoparticles were synthesized by the citric acid sol-gel route using tetrabutyl titanate and yttria as starting materials. Anhydrous citric acid (CA, $\mathrm{C}_{6} \mathrm{H}_{8} \mathrm{O}_{7}$, A.R.) and absolute ethanol $\left(\mathrm{C}_{2} \mathrm{H}_{5} \mathrm{OH}\right.$, A.R.) were used as chelator and solvent, respectively. Tetrabutyl titanate $\left[\mathrm{Ti}(\mathrm{OBu})_{4}\right.$, A.R.] and yttria $\left(\mathrm{Y}_{2} \mathrm{O}_{3}, 99.99 \%\right)$ were used as the precursors of $\mathrm{Ti}$ and $\mathrm{Y}$, respectively. The molar rate of $\mathrm{Ti} / \mathrm{Y}$ was determined at $1 / 1$, and the amount of citric acid was controlled at $n_{\mathrm{CA}} /\left(n_{\mathrm{Y}}+n_{\mathrm{Ti}}\right)=2 \cdot 5$. First a given amount of $\mathrm{Y}_{2} \mathrm{O}_{3}$ was dispersed in a spot of water and then concentrated $\mathrm{HNO}_{3}$ was added to it dropwise to dissolve the rareearth oxide under magnetic stirring, and the excessive $\mathrm{HNO}_{3}$ was removed completely by slow heating. Subsequently, an appropriate amount of citric acid was dissolved thoroughly in absolute ethanol, and the stoichiometric ratio, $\mathrm{Ti}(\mathrm{OBu})_{4}$, was added drop by drop and the mixture was stirred vigorously until it became homogeneous transparent solution. The solution was poured into the upper solution. The mixture solution was placed in an $80^{\circ} \mathrm{C}$ water bath to vapourize water and excessive solvent, then became highly viscous, and, finally, changed into transparent glassy gel. Noteworthy is that no visible formation of precipitation or turbidity was observed during chelation or gelation. Xerogel is called dried precursor of $\mathrm{Y}_{2} \mathrm{Ti}_{2} \mathrm{O}_{7}$, which was heat-treated at desired temperatures $\left(700-900^{\circ} \mathrm{C}\right)$ in static air on an $\mathrm{Al}_{2} \mathrm{O}_{3}$ boat with a heating rate of $5^{\circ} \mathrm{C} / \mathrm{min}$ and dwelling time of $1 \mathrm{~h}$, followed by furnace cooling to room temperature naturally. For comparison, yttrium titanate was also prepared from stoichiometric mixture of yttria and titania by traditional solid state reaction (SSR) according to Ault and Welch (1966).

\subsection{Characterization of yttrium titanate nanoparticles}

FT-IR spectra (FT-IR Avatar 380, Thermo Nicolet Corporation, USA) was utilized to monitor the structural changes of compounds with a scan range of $4000-400 \mathrm{~cm}^{-1}$ during the preparative process. Thermogravimetry (TG) and differential thermal analysis (DTA) (TG/DTA851, MAC Science Company, Tokyo, Japan) were operated with the calefactive velocity of $10^{\circ} \mathrm{C} / \mathrm{min}$ in air atmosphere to follow the physicochemical changes of xerogel during calcination. The crystalline phase structure of products was determined by X-ray diffraction analysis (XRD; Rigaku $\mathrm{D} / \mathrm{max}-2000)$ using $\mathrm{CuK}_{\alpha}$ radiation, $\lambda=0.154056 \mathrm{~nm}$, $40 \mathrm{kV} / 300 \mathrm{~mA}$, scan rate of $2 \theta 4 \% \mathrm{~min}$, scan range of $(2 \theta)$ $\left.10-80^{\circ}\right)$. Nanocrystallite sizes were estimated from XRD spectra by use of Scherrer's equation:

$$
D=(k \lambda) /(\beta \cos \theta),
$$

where $D$ is the grain size, $k$ a constant (shape factor), $\lambda$ the X-ray wavelength, $\beta$ the full-width-at-half-maximum (FWHM) of a characteristic diffraction peak and $\theta$ the diffraction angle. The microstructures and average size of samples were examined by transmission electron microscopy (TEM, JEOL-2010F/2200Fs, Japan) with an accelerating voltage of $200 \mathrm{kV}$, while the atomic composition was determined using an EDX spectrometer attached to the FESEM (FESEM, JSM-7001F, JEOL Japan). TEM samples were prepared by dispersing the powder in absolute alcohol by ultrasonic treatment, dropping onto a porous carbon film supported on a copper grid, and then dried in air. The BrunauerEmmett-Teller (BET) surface area was evaluated by the amount of nitrogen adsorption at $77 \mathrm{~K}$ in a constant volume adsorption apparatus (Coulter SA 3100).

\section{Results and discussion}

\subsection{FT-IR spectra}

FT-IR spectra were used to monitor the structural changes of compounds during the process to investigate the reaction and uniform distribution mechanism of reactants during the preparative process. It can be seen that strong coordination interaction existed between metal precursors and citric acid. The bands around $3435 \mathrm{~cm}^{-1}$ and $1636.8 \mathrm{~cm}^{-1}$ are attributed to the stretching vibration of hydroxyl group, $\mathrm{OH}$ (Li et al 2006a), for which moisture present in the samples can be accounted. The absorption peaks around $1385 \mathrm{~cm}^{-1}$ are assigned to the symmetric vibration mode of carbonyl groups due to the adsorption of $\mathrm{CO}_{2}$ molecule in the samples. Comparing figure 1(a) to figure 2(b), the band around $1730 \cdot 3 \mathrm{~cm}^{-1}$, which is the stretching vibration of $\mathrm{C}=\mathrm{O}$ in $-\mathrm{COOH}$, disappeared in the products calcined at $750^{\circ} \mathrm{C}$. Two bands at 1398.8 and $1204 \mathrm{~cm}^{-1}$ was observed in the xerogel, which are ascribed to the $\mathrm{COO}-$ stretching vibration for $\mathrm{Ti}^{4+}-$ carboxylic acid complex (Xiong et al 1997) and $\mathrm{Y}^{3+}$ - carboxylic acid complex (Akcora et al 2005), respectively, suggesting that there existed strong coordination interaction between $\mathrm{Ti}^{4+}, \mathrm{Y}^{3+}$ and citric acid. Both the bands disappeared when the precursor was calcined at $750^{\circ} \mathrm{C}$. In addition, two bands at $560.5 \mathrm{~cm}^{-1}$ and $460.2 \mathrm{~cm}^{-1}$ were observed in precursor gel, which was assigned to the stretching vibration of Ti-O and $\mathrm{Y}_{-} \mathrm{O}^{\prime}$, respectively (Coutier et al 2001). In $\mathrm{Y}_{2} \mathrm{Ti}_{2} \mathrm{O}_{7}$ powder, however, the bands at $568.2 \mathrm{~cm}^{-1}$, $468.3 \mathrm{~cm}^{-1}$ and $410 \mathrm{~cm}^{-1}$ are ascribable to Ti-O, Y-O' $\mathrm{O}^{\prime}$ and $\mathrm{Y}-\mathrm{O}$ stretching vibration, respectively which are the main features of the titanate pyrochlore spectra (Subramanian et al 1983). The slight difference of the absorption position of $\mathrm{Ti}-\mathrm{O}$ and $\mathrm{Y}_{-} \mathrm{O}^{\prime}$ in precursor and $\mathrm{Y}_{2} \mathrm{Ti}_{2} \mathrm{O}_{7}$ powder, can be explained as the different chemical environment. Owing to 


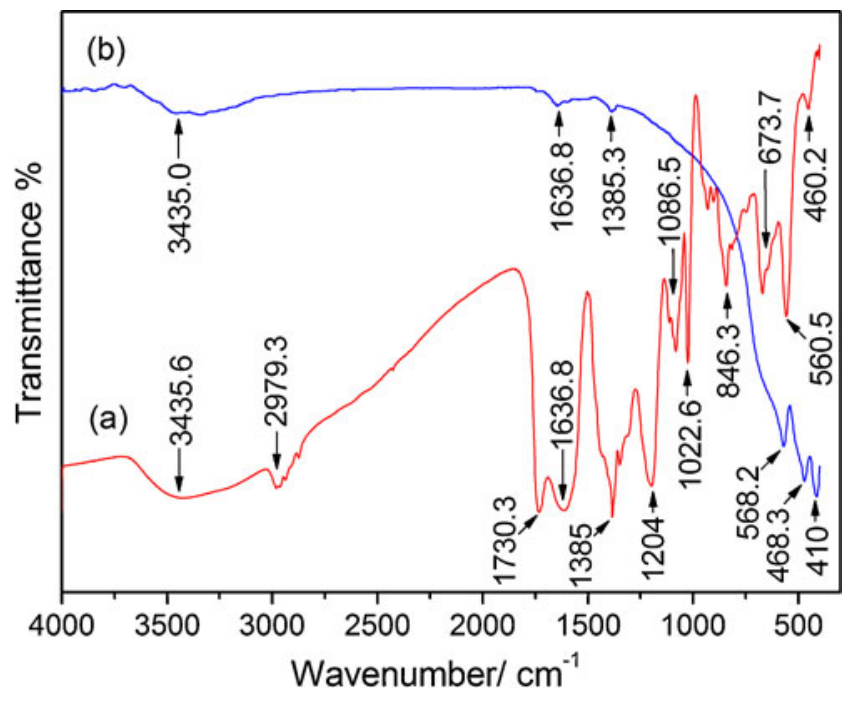

Figure 1. FT-IR spectra of (a) $\mathrm{Y}_{2} \mathrm{Ti}_{2} \mathrm{O}_{7}$ xerogel and (b) $\mathrm{Y}_{2} \mathrm{Ti}_{2} \mathrm{O}_{7}$ calcined at $750^{\circ} \mathrm{C}$.

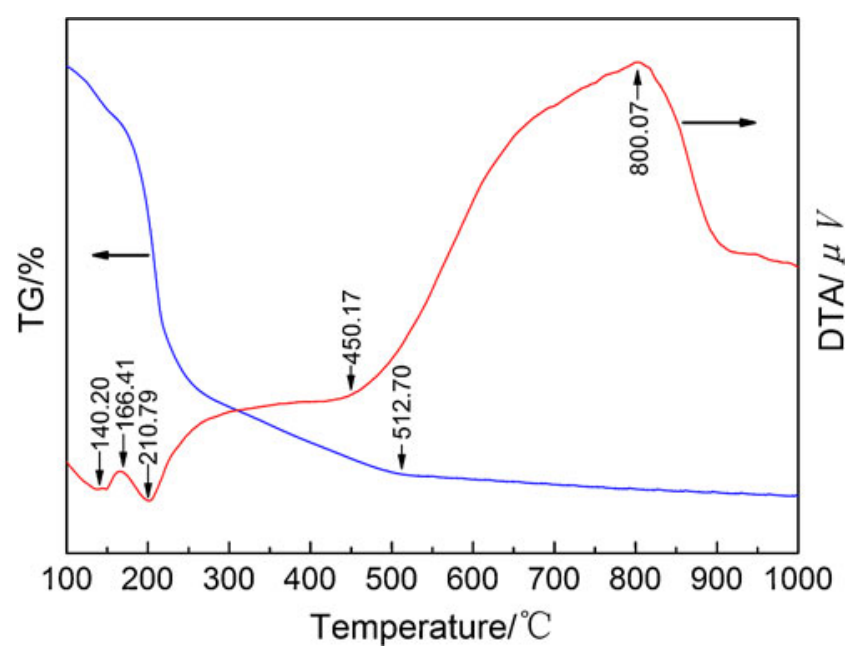

Figure 2. TG-DTA curve of $\mathrm{Y}_{2} \mathrm{Ti}_{2} \mathrm{O}_{7}$ xerogel in the temperature range $100-1000^{\circ} \mathrm{C}$.

the strong interaction between metal ions and citric acid, $\mathrm{Ti}^{4+}$ and $\mathrm{Y}^{3+}$ were uniformly and highly dispersed in citric acid, achieving molecular level distribution, which may help to dramatically lower the calcining temperature and make sure that the as-obtained products are ultrafine and ultrapure. This supposition was fully confirmed by XRD results below.

\section{$3.2 T G-D T A$}

TG-DTA experiment was utilized in order to determine the decomposition of precursor and the transformation of $\mathrm{Y}_{2} \mathrm{Ti}_{2} \mathrm{O}_{7}$ crystal phase. The TG curve shows a continuous weight loss up to about $512^{\circ} \mathrm{C}$, the weight loss is due to dehydration and decomposition of the organics. As seen in the DTA curve, the first endothermic peak $\left(140 \cdot 20^{\circ} \mathrm{C}\right)$ is assigned to the volatilization and desorption of water and ethanol. The second endothermic peak $\left(210 \cdot 79^{\circ} \mathrm{C}\right)$ is caused by the evaporation and burning of organic substances. A large exothermic range $\left(250-450^{\circ} \mathrm{C}\right)$ is observed, which is attributed to the combustion of citric acid complex. The broad and strong exothermic peak $\left(800^{\circ} \mathrm{C}\right)$ is related to the crystal lattice energy by the formation of pyrochlore oxide phase and its complete crystallization. No further weight loss was found up to $900^{\circ} \mathrm{C}$, indicating that the $\mathrm{Y}_{2} \mathrm{Ti}_{2} \mathrm{O}_{7}$ crystals can be prepared at lower temperature by citric acid solgel method. The results are in good agreement with XRD experiments.

\section{$3.3 X R D$}

Figure 3 shows the XRD patterns of the $\mathrm{Y}_{2} \mathrm{Ti}_{2} \mathrm{O}_{7}$ powders by CAM calcined in static air at various temperatures (700$900^{\circ} \mathrm{C}$ ) for $1 \mathrm{~h}$. It is obvious that the precursor heat-treated at $700^{\circ} \mathrm{C}$ for $1 \mathrm{~h}$ is primarily amorphous as shown by the broad continuum in XRD pattern in figure 3(a). Dramatic crystallization has occurred during the calcination of precursor at $750^{\circ} \mathrm{C}$ for $1 \mathrm{~h}$. And all of the XRD reflections of precursor that has been heat-treated at temperature above $750^{\circ} \mathrm{C}$ exhibit single phase $\mathrm{Y}_{2} \mathrm{Ti}_{2} \mathrm{O}_{7}$ with a pyrochlore structure, the XRD pattern of which is indexed based on face-centred cubic lattice ( $a=10.089 \AA$ ) as reported previously (JCPDS No. 89-2065) (Brixner 1964). Additionally, with the increase of calcination temperature, the intensity of each peak grew and the position of $2 \theta$ indicating a pyrochlore structure did not change, which means that during the calcination step, no other impure phases such as $\mathrm{Y}_{2} \mathrm{O}_{3}$ and $\mathrm{TiO}_{2}$ were formed.

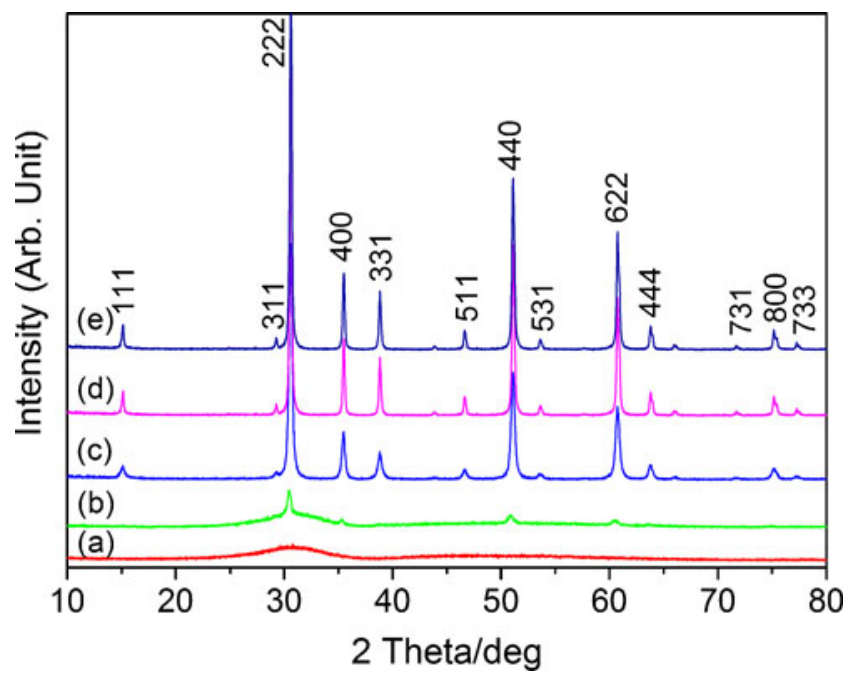

Figure 3. XRD patterns of $\mathrm{Y}_{2} \mathrm{Ti}_{2} \mathrm{O}_{7}$ calcined at different temperatures by citric acid (a) $700^{\circ} \mathrm{C}$, (b) $725^{\circ} \mathrm{C}$, (c) $750^{\circ} \mathrm{C}$, (d) $800^{\circ} \mathrm{C}$ and (e) $900^{\circ} \mathrm{C}$. 
Therefore, before the calcination step, the two components ( $\mathrm{Y}$ and $\mathrm{Ti}$ ) in the xerogel were almost homogeneous. And also, based on the Scherrer equation, the average grain size of $\mathrm{Y}_{2} \mathrm{Ti}_{2} \mathrm{O}_{7}$ obtained from a calcining temperature of $750^{\circ} \mathrm{C}$ was about $25 \mathrm{~nm}$ (the value is calculated by FWHM of the most intense line at the diffraction angle $2 \theta 30.58$ which is $0 \cdot 342$ ), which is fully confirmed by TEM results below.

For the solid-state reaction route (see figure 4), however, no $\mathrm{Y}_{2} \mathrm{Ti}_{2} \mathrm{O}_{7}$ phase was observed in the product when calcinated at $750^{\circ} \mathrm{C}$, only the phase of anatase-type $\mathrm{TiO}_{2}$ and $\mathrm{Y}_{2} \mathrm{O}_{3}$ were detected. When the sample was heated at $1100^{\circ} \mathrm{C}$, the pyrochlore structure was identified, and also there existed still the phase of unreacted rutile-type $\mathrm{TiO}_{2}$ and $\mathrm{Y}_{2} \mathrm{O}_{3}$. Only when the temperature was raised to $1500^{\circ} \mathrm{C}$ and the calcination time was extended to $10 \mathrm{~h}$, a pure phase of $\mathrm{Y}_{2} \mathrm{Ti}_{2} \mathrm{O}_{7}$ was completely formed. These results indicate that the pyrochlore oxide $\mathrm{Y}_{2} \mathrm{Ti}_{2} \mathrm{O}_{7}$, which usually forms at high temperature in conventional method $\left(1500^{\circ} \mathrm{C}\right)$ with a long reaction time (10 h) (Ault and Welch 1966), can be successfully synthesized at a relatively low temperature $\left(750^{\circ} \mathrm{C}\right)$ with shortened reaction time $(1 \mathrm{~h})$ by the modified sol-gel method. This technique is beneficial to energy-saving and environment pollution; and it is a cheap and green approach to achieve excellent pyrochlore oxides.

\subsection{TEM and EDX spectra}

Transmission electron microscopy (TEM) was employed to obtain direct information about the size and structure of the prepared $\mathrm{Y}_{2} \mathrm{Ti}_{2} \mathrm{O}_{7}$ nanocrystals. The TEM results of $\mathrm{Y}_{2} \mathrm{Ti}_{2} \mathrm{O}_{7}$ prepared from a calcining temperature of $750^{\circ} \mathrm{C}$ with dwelling time of $1 \mathrm{~h}$ are shown in figure 5. From figure 5(a), it can be found that quasi-spherical $\mathrm{Y}_{2} \mathrm{Ti}_{2} \mathrm{O}_{7}$ nanoparticles have good dispersibility, and the average size

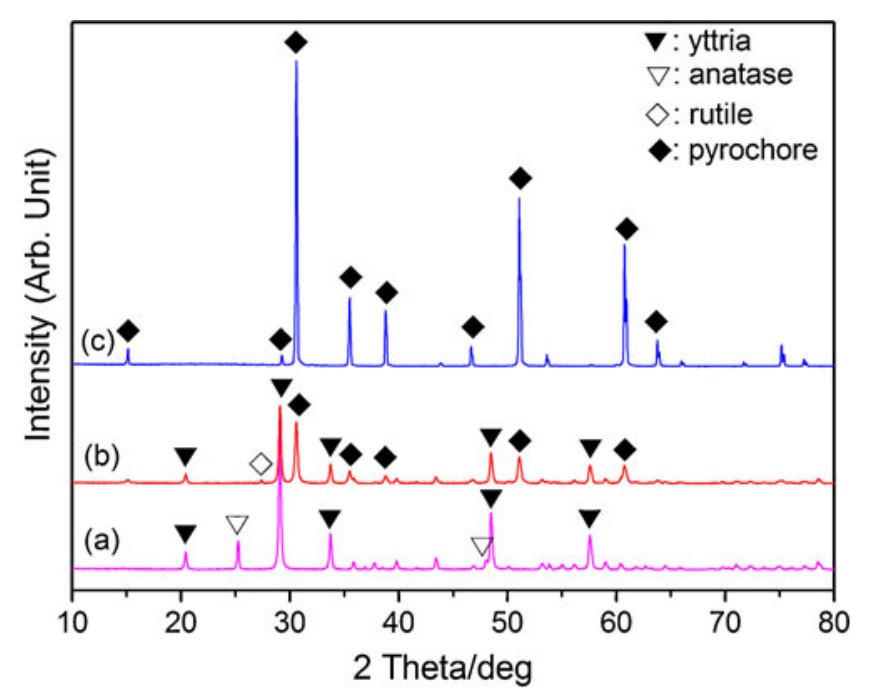

Figure 4. XRD patterns of $\mathrm{Y}_{2} \mathrm{Ti}_{2} \mathrm{O}_{7}$ calcined at different temperatures by solid-state reaction: (a) $750^{\circ} \mathrm{C}$, (b) $1100^{\circ} \mathrm{C}$, (c) $1500^{\circ} \mathrm{C}$.
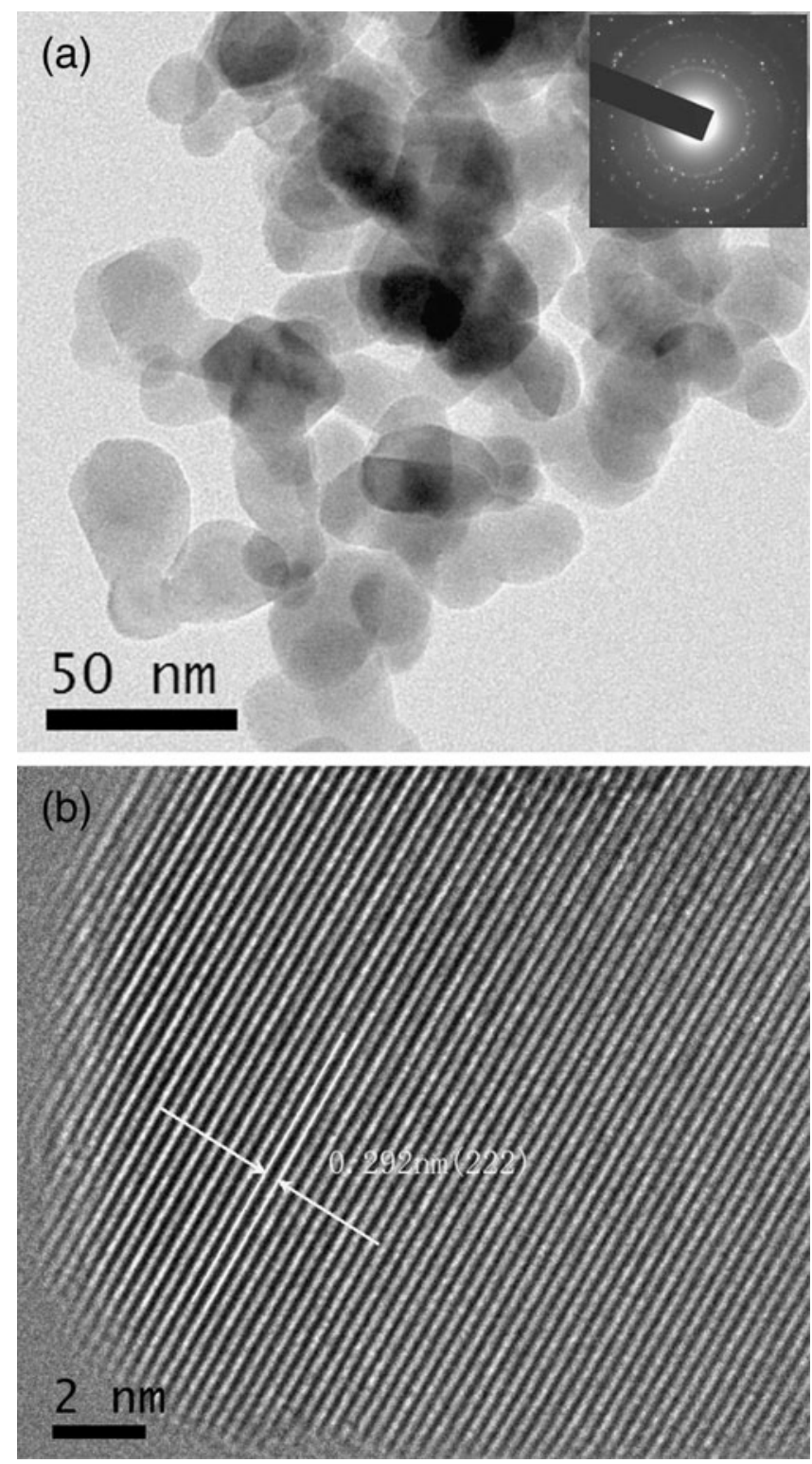

Figure 5. TEM micrographs of $\mathrm{Y}_{2} \mathrm{Ti}_{2} \mathrm{O}_{7}$ calcined at $750^{\circ} \mathrm{C}$ for $1 \mathrm{~h}$ by modified sol-gel method: (a) TEM, (b) HRTEM. The inset in (a) shows the corresponding electron diffraction patterns.

estimated from TEM is around 20-30 nm, which is quite consistent with XRD results. The inset in figure 5(a) shows the corresponding electron diffraction patterns, which is the characteristic rings of nano-polycrystals. In figure 5(b), typical high-resolution transmission electron microscopy (HRTEM) images indicate clear and regular crystal lattice distance suggesting that highly crystalline $\mathrm{Y}_{2} \mathrm{Ti}_{2} \mathrm{O}_{7}$ were formed. The lattice fringes with an interplanar distance of $0.292 \mathrm{~nm}$ obtained from the HRTEM images was attributed to the (222) plane of the cubic structure. According to the EDX analysis, it can be seen that there is no other element than $\mathrm{Y}, \mathrm{Ti}$ and $\mathrm{O}$ on the product surface (figure 7), and the atomic ratio of Y:Ti:O is $18 \cdot 15: 18 \cdot 20: 63.65$ (see the inset 


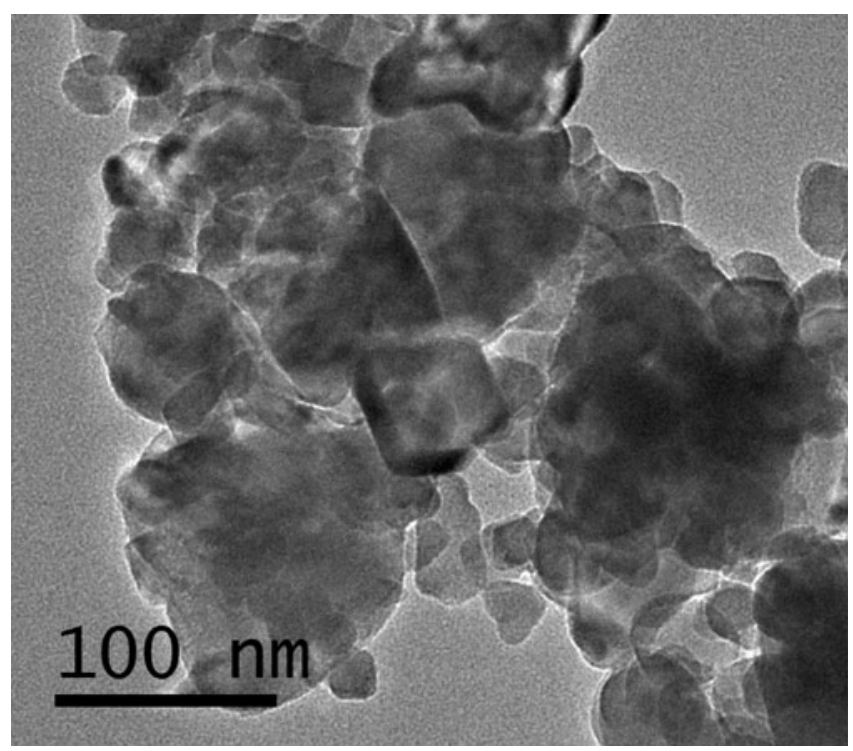

Figure 6. TEM image of $\mathrm{Y}_{2} \mathrm{Ti}_{2} \mathrm{O}_{7}$ calcined at $1500^{\circ} \mathrm{C}$ for $8 \mathrm{~h}$ via solid state reaction route.

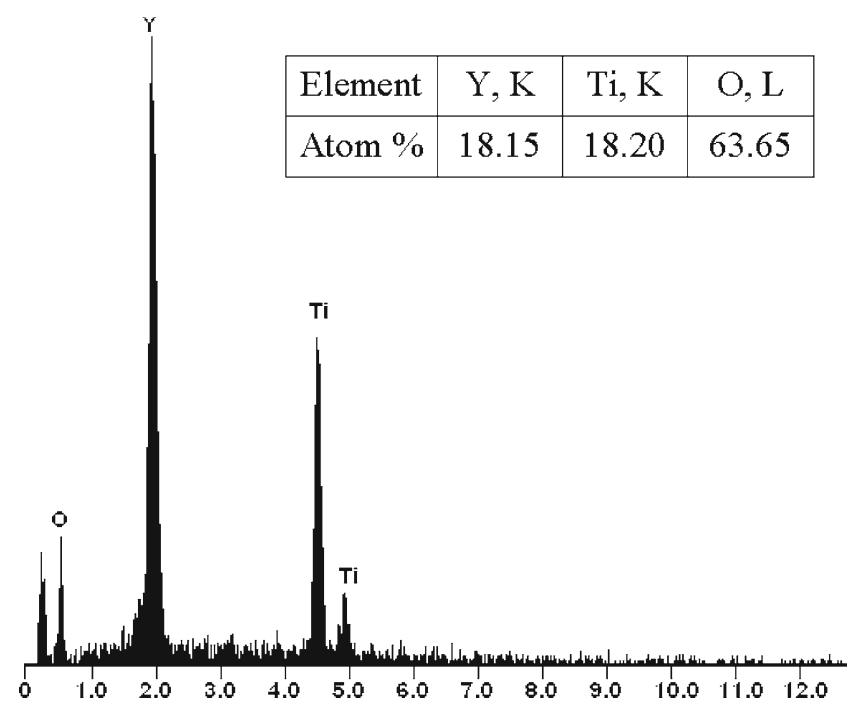

Figure 7. EDX spectrum of $\mathrm{Y}_{2} \mathrm{Ti}_{2} \mathrm{O}_{7}$ calcined at $750^{\circ} \mathrm{C}$ for $1 \mathrm{~h}$ by modified sol-gel method.

in figure 7), suggesting that the $n_{\mathrm{Y}}: n_{\mathrm{Ti}}: n_{\mathrm{O}}$ is $2: 2: 7$, which is uniform to the theoretical composition.

For comparison, the morphology and dispersibility of $\mathrm{Y}_{2} \mathrm{Ti}_{2} \mathrm{O}_{7}$ fabricated by solid-state reaction were also presented (see figure 6). The morphology and dispersibility were quite different from those of modified sol-gel method. It was very difficult to identify the morphology of $\mathrm{Y}_{2} \mathrm{Ti}_{2} \mathrm{O}_{7}$ and its dispersibility was quite low. So the catalytic activity of $\mathrm{Y}_{2} \mathrm{Ti}_{2} \mathrm{O}_{7}$ may be restricted by these two aspects. And also, the BET surface area of $\mathrm{Y}_{2} \mathrm{Ti}_{2} \mathrm{O}_{7}$ calculated from $\mathrm{N}_{2}$ isotherms at $77 \mathrm{~K}$ was about $50 \mathrm{~m}^{2} / \mathrm{g}$, and is quite larger than those of traditional solid-state reaction products $\left(5 \mathrm{~m}^{2} / \mathrm{g}\right)$ and other soft-chemistry routes (Rao et al 2007). These excellent physical properties of the samples obtained by citric acid method, such as more regular morphology, higher dispersibility, and larger BET surface area may result in better behaviour in hydrogen storage and photocatalytic reaction.

\section{Conclusions}

Pyrochlore-type yttrium titanate nanoparticles were prepared by citric acid sol-gel process at $750^{\circ} \mathrm{C}$ for $1 \mathrm{~h}$. The obtained $\mathrm{Y}_{2} \mathrm{Ti}_{2} \mathrm{O}_{7}$ is nearly sphere-like and exhibits good crystallinity, smaller average size $(20-30 \mathrm{~nm})$ and larger BET surface area $\left(50 \mathrm{~m}^{2} / \mathrm{g}\right)$. This research provides a simple soft-chemistry route to synthesize nanoscale pyrochlore-oxide $\mathrm{Y}_{2} \mathrm{Ti}_{2} \mathrm{O}_{7}$ at lower temperatures and with shortened reaction time. This approach can also be applied for the preparation of other pyrochlore oxides nanoparticles.

\section{Acknowledgements}

The funding for projects came from the Natural Science Foundation of China (No. 50634060), the Science Centre of Phase Diagrams \& Materials Design and Manufacture and Natural Science, Foundation of Jiangxi Province (No. 2009GZH0002 and No. 2009GZH0004). The support from the Special Talents of Higher Education Office of Guangdong Province is greatly appreciated.

\section{References}

Abe R, Higashi M, Sayama K, Abe Y and Sugihara H 2006 J. Phys. Chem. B110 2219

Akcora P, Zhang X, Varughese B, Briber R M and Kofinas P 2005 Polymer 465194

Ault J and Welch A 1966 Acta Crystallogr. 20410

Brixner L 1964 Inorg. Chem. 31065

Coutier C, Meffre W, Jenouvrier P, Fick J, Audier M, Rimet R, Jacquier B and Langlet M 2001 Thin Solid Films 39240

Erickson E E, Gray D, Taylor K, Macaluso R T, LeTard L A, Lee G S and Chan J Y 2002 Mater. Res. Bull. 372077

Ewing R C, Weber W J and Lian J 2004 J. Appl. Phys. 955949

Hector A L and Wiggin S B 2004 J. Solid State Chem. 177139

Higashi M, Abe R, Sayama K, Sugihara H and Abe Y 2005 Chem. Lett. 341122

Ishida S, Ren F and Takeuchi N 1993 J. Am. Ceram. Soc. 762644

Jenouvrier P, Boccardi G, Fick J, Jurdyc A M and Langlet M 2005 J. Lumin. 113291

Li G Z, Yu M, Wang R S, Wang Z L, Quan Z W and Lin J 2006a J. Mater. Res. 212232

Li K W, Wang H and Yan H 2006b J. Mol. Catal. A: Chem. 24965 Lin K M, Lin C C, Hsiao C Y and Li Y Y 2007 J. Lumin. 127561

Pace S, Cannillo V, Wu J, Boccaccini D N, Seglem S and Boccaccini A R 2005 J. Nucl. Mater. 34112

Pailh N, Gaudon M and Demourgues A 2009 Mater. Res. Bull. 44 1771

Pechini M 1967 US Patent 3330697 
Rao K K, Anantharamulu N, Salagram M and Vithal M 2007 Spectrochim. Acta Part A $\mathbf{6 6} 646$

Shlyakhtina A V, Savvin S N, Levchenko A V, Boguslavskii M V and Shcherbakova L G 2008 Solid State Ionics 179985

Stanek C R, Minervini L and Grimes R W 2002 J. Am. Ceram. Soc. 852792

Subramanian M A, Aravamudan G and Subba Rao G V 1983 Prog. Solid State Chem. 1555
Tang Z, Zhou L, Yang L and Wang F 2009 J. Alloys Compd 481704 Ting C C, Chang C W, Chuang L C, Li C H and Chiu Y S 2010 Thin Solid Films $\mathbf{5 1 8} 5704$

Wuensch B J et al 2000 Solid State Ionics 129111

Xiong G, Zhi Z L, Yang X J, Lu L D and Wang X 1997 J. Mater. Sci. Lett. 161064

Zhang L, Zhang W, Zhu J, Hao Q, Xu C, Yang X, Lu L and Wang $\mathrm{X} 2009$ J. Alloys Compd $\mathbf{4 8 0}$ L45 